\title{
Robotic breast surgery: the pursue for excellence in treatment and satisfaction - a review
}

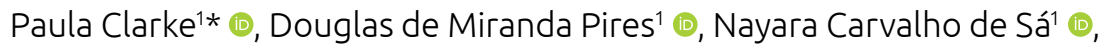

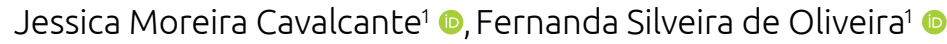

\section{ABSTRACT}

Introduction: Nipple sparing mastectomy (NSM) with immediate reconstruction is an option for the treatment of breast cancer or for risk-reducing surgery. This technique offers good aesthetic results without compromising oncological safety. Robotic nipple sparing mastectomy (RNSM) was first described in 2015 and has been executed in various centers ever since, but the costeffectiveness and oncological safety of this technique are still questioned. Objectives: The primary aim of this study was to critically review the literature and discuss the feasibility, advantages and limitations of robotic breast surgery. Methods: Search in PubMed database for publications related to "robotic breast surgery". Selection and review of relevant articles, and analysis of results from these studies. Results: Our search comprised the period between 2015 and 2019. The rates of complications were low and the learning curve is apparently rapid, though there is still a lack of data involving cost-effectiveness. Conclusions: RNSM with immediate reconstruction is a great advance in the surgical treatment for breast cancer. Cost-effectiveness and oncological safety must still be accessed through randomized clinical trials.

KEYWORDS: breast neoplasms; robotic surgical procedures; mastectomy, subcutaneous; breast implants.

\section{INTRODUCTION}

Breast cancer diagnosis and surgery have evolved toward less invasive procedures throughout the years. Breast conserving surgeries are largely carried out and mastectomies no longer have to be disfiguring. More than ever, breast surgeons are committed to improve their techniques in order to offer better aesthetic outcomes, which relate to better quality of life and self-image appreciation ${ }^{1}$.

Nipple sparing mastectomy (NSM) was described in 1984 by Hinton et al. as a safe alternative to simple mastectomy. In a series of 98 patients submitted to subcutaneous mastectomy, the skin envelope was preserved and reconstruction was performed about 6 months later; there was no increase in local recurrence of the skin flaps in a follow-up of 30 months $^{2}$. The term NSM with immediate reconstruction was first used by Toth and Lappert in 1991, and in the same year by Kroll et al., who published a series of 104 cases, with similar local recurrences, after a mean followup of 5.6 years $^{3,4}$. NSM is nowadays an option for the treatment of breast cancer, when following appropriate indications, and also for risk-reducing surgery, offering good aesthetic results without compromising oncological safety ${ }^{5}$.

More recently, endoscopic breast surgery was attempted, but due to technical difficulties, it was not adopted in clinical practice $^{6,7}$. In the context of minimally invasive approaches, the use of robotic surgery has become popular in urologic, gynecological, and colorectal procedures, and more recently, in the fields of thyroidectomy, oropharyngeal, and plastic surgery? The first report of breast robotic surgery happened in 2015 by Toesca et al., who performed robotic nipple sparing mastectomy (RNSM) ${ }^{8}$ with a DaVinci S robotic platform and since then a similar procedure has been executed in other centers. Surgeons claim that the advantages of RNSM are better aesthetic outcomes, with minimal scars hidden under the arm, enhanced precision with three-dimensional optics, reduced tremor and less bleeding ${ }^{7-10}$. The objective of this review was to discuss the feasibility, advantages, and limitations of robotic breast surgery, especially RNSM.

${ }^{1}$ Clínica de Mastologia, Santa Casa de Belo Horizonte - Belo Horizonte (MG), Brazil.

*Corresponding author: drapaulaclarke@gmail.com

Conflict of interests: nothing to declare.

Received on: 08/24/2019. Accepted on: 11/12/2019 


\section{METHODS}

A search was performed in PubMed database for articles related to robotic breast surgery, published from 2015, year known to be the first report, until June 2019. The search identified 163 related articles. Titles that did not relate to breast surgery or breast cancer were excluded. This resulted in 27 abstracts to be read, which mentioned internal mammary robotic surgery, robotic harvesting of flaps, or RNSM with or without robotic reconstruction. Only the 19 abstracts mentioning RNSM were considered and read in their entirety. Of these, six were selected to analyze the data, excluding duplicates, editorials, letters to the editor, or response to letters to the editor. Surgeries performed in cadavers were not included in the data analysis, but considered for technical detail information.

\section{RESULTS}

The first report of RNSM was carried out in 2015 by Toesca in the Istituto Europeo di Oncologia (IEO), with the objective to study an innovative technique and overcome the limitations of the endoscopic approach. Three patients with BRCA mutations, previously treated for unilateral breast cancer, who wanted to undergo a contralateral risk-reducing surgery were submitted to the procedure $^{8}$. Following this, Sarfati et al. conducted a similar procedure on breasts of two fresh female cadavers?.

Since then, other centers have published their cases, describing different aspects in positioning, incision, complications, and follow-up results. Studies data are summarized in Table 1.

\section{Patients}

The studies involve a total of 160 patients. Toesca et al. ${ }^{7}$ reported that their first three cases were prophylactic contralateral RNSM in patients previously treated for breast cancer, but after they gained knowledge of how to remove the gland, they extended the indication for patients with breast cancer, reporting a total of 29 RNSM in 24 women. The tumor had to be situated at least $1 \mathrm{~cm}$ from the nipple areola complex (NAC), in patients with no associated comorbidities, body mass index $(\mathrm{BMI})<25$, and who were at low risk for anesthesia. Exclusion criteria were: grade 2 ptosis or higher, diabetes, heavy smoking, obesity or previous radiation therapy. In 2016, Sarfati et al. reported their first experience with RNSM in two fresh female cadavers ${ }^{11}$, and later in June 2018, published their study involving 62 prophylactic, and only 1 therapeutic RNSM 9 . The breasts had ptosis grade 1 or 2 , they were of small breast cup size, the tumor had to be at least $2 \mathrm{~cm}$ away from the NAC, and a high-risk genetic mutation had been identified in the prophylactic group. Patients were excluded if they had a history of breast surgery or radiation, if post-operative radiation was required, and also heavy smokers or patients with uncontrolled diabetes mellitus. Lai et al. ${ }^{10}$ performed 39 RNSM in 33 women, most of which ( 35 breasts) were therapeutic. Patients were diagnosed with ductal carcinoma in situ (DCIS) or invasive breast cancer stages I, II, or IIIA, with a tumor size $<5 \mathrm{~cm}$ and no evidence of multiple lymph node metastasis. Patients with severe comorbidities, skin, chest or nipple invasion, locally advanced or inflammatory disease were excluded. Houvenaeghel et al. ${ }^{12}$ performed 27 RNSM in 17 patients with primary breast cancer and 10 with local recurrences. Characteristics of patients were determined and they were divided into three groups, each with different approaches for breast dissection. Park et al. ${ }^{13}$ and Rajappa et al. ${ }^{14}$ describe each, their experience with 1 case only.

\section{Positioning}

Toesca et al. first described a flat supine position, with the arm above the head, internal rotation, and $90^{\circ}$ abduction, lying on a chopping block placed under the back ${ }^{8}$, but this patient developed a temporary biceps brachii strength reduction. Because of that, in the following cases, the upper arm hung normally alongside the body, and the elbow was bent at about $30^{\circ}$ so that the hand, wrist, and forearm were straight and roughly parallel to the floor at the side of the bed? Sarfati and Lai describe a supine position with abduction at $90^{\circ}$ of the $\mathrm{arm}^{9,10}$. Houvenaeghel et al. and Park et al. describe a supine, dorsal decubitus, with ante-flexion of the $\operatorname{arm}^{12,13}$. Rajappa et al. reported positioning as Toesca's et al. ${ }^{14}$.

\section{Incision and technique}

Different techniques were described, though having one thing in common: an incision under the axilla, hidden by the arm. Incision size varied from as small as 2.5 to $6 \mathrm{~cm}$, in the mid-axillary or anterior axillary line. This size is mainly determined by the size of the breast to be removed through the same incision. In some series, a second small incision was made inferior to the first, in order to insert another trocar and the drain at the end of the procedure ${ }^{9,12}$. Most studies describe subcutaneous flap dissection with nonrobotic scissors or electrocautery $y^{7,913,14}$ to gain space for placing the port and docking. Houvenaeghel et al. ${ }^{12}$ divided their patients into three groups in order to compare time of procedures:

- group 1: dissection with robotic scissors using coagulation; - group 2: dissection with robotic scissors without coagulation; - group 3: dissection with non-robotic scissors after subcutaneous infiltration with adrenaline serum and then robotic dissection.

Except for Park et al. ${ }^{13}$, who used no gas but retractors to maintain the working space, all other surgeries were performed under

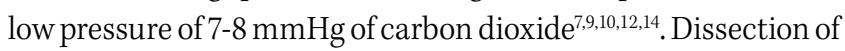
the gland was performed with monopolar curved-scissors or cautery, moving from the axilla toward the nipple areola complex, medially, superiorly and inferiorly around the breast. An intraoperative biopsy of the retroareolar region in therapeutic surgeries was usually done with intraoperative frozen sections in series by Toesca et al. and Park et al. Lymph node dissection was performed through axillary incision, so as the removal of breast 
gland, placement of prosthesis and, in cases of reconstruction with the latissimus dorsi, dissection of the flap were also done through the same incision.

\section{Surgery time}

It is understandable that with a new technique, surgical time will be long. The first operation by Toesca et al. took 7 hours, needing conversion to open surgery, due to prolonged surgery time ${ }^{8}$. The last cases were completed in about 3 hours, including docking, dissection and reconstruction. All studies report the same outline, with a fast learning curve. In Houvenaeghel et al.s study, the different groups had very different surgery times, and the longest procedures were those with robotic dissection ${ }^{12}$. According to Lai et al., the larger the breast, the longer time was needed in the initial cases, but operation time decreased significantly in the mature phase and did not fluctuate with specimen weight ${ }^{10}$. Another factor that has influence over surgical time is the prophylactic or therapeutic indication of procedure, because of the need to do a biopsy of retroareolar region, with intraoperative frozen section. Surgical time data can also be visualized in Table 1.

\section{Complications}

The rate of complications or conversions in the studies was low, most of them classified as minor complications, grade I, II or III, according to the Clavien-Dindo classification ${ }^{15}$ (Figure 1). Erythema was described in one patient; small blistering of the skin, caused by electrocautery was reported in four patients. Seroma needing aspiration in one patient; dorsal lymphocele in one patient; and hematoma needing operation in one patient. Neuropraxia happened in two cases, both temporary. One axillary delayed wound healing was reported. There was partial nipple ischemia in four patients, partial skin flap (not

Table 1. Summary of studies data.

\begin{tabular}{|c|c|c|c|c|c|c|c|}
\hline Study & Patients & Positioning & Incision & Surgery Time & $\begin{array}{l}\text { Oncological } \\
\text { Outcomes }\end{array}$ & Satisfaction & $\begin{array}{l}\text { Cost- } \\
\text { effectiveness }\end{array}$ \\
\hline Toesca et al. ${ }^{7}$ & $\begin{array}{l}24 \text { patients - } \\
29 \text { breasts: } 21 \\
\text { therapeutic; } 8 \\
\text { prophylactic } \\
\text { RNSM }\end{array}$ & $\begin{array}{l}\text { Flat supine } \\
\text { position; arm } \\
\text { alongside the } \\
\text { body }\end{array}$ & $\begin{array}{c}3 \mathrm{~cm} \text { on } \\
\text { midaxillary line }\end{array}$ & $\begin{array}{l}420 \text { min (first } \\
\text { case); } 180 \mathrm{~min} \\
\text { (last cases) }\end{array}$ & $\begin{array}{l}\text { No } \\
\text { recurrence. } \\
8 \text { months } \\
\text { follow-up }\end{array}$ & $\begin{array}{l}\text { High } \\
\text { degree* }\end{array}$ & N/A \\
\hline Sarfati et al. ${ }^{9}$ & $\begin{array}{l}33 \text { patients - } \\
63 \text { breasts; } 1 \\
\text { therapeutic; } 62 \\
\text { prophylactic } \\
\text { RNSM }\end{array}$ & $\begin{array}{l}\text { Supine; } 90^{\circ} \\
\text { abduction of } \\
\text { the arm }\end{array}$ & $\begin{array}{c}\text { Vertical } \\
3-5 \mathrm{~cm}+\text { a } \\
\text { subcentimeter } \\
\text { incision } 8-9 \mathrm{~cm} \\
\text { below, } 6-7 \mathrm{~cm} \\
\text { posterior from } \\
\text { the lateral- } \\
\text { mammary fold }\end{array}$ & $\begin{array}{l}195 \text { min (first } \\
\text { case); } 85 \text { min } \\
\text { (last cases) }\end{array}$ & $\begin{array}{l}\text { No } \\
\text { recurrence. } \\
9 \text { months } \\
\text { follow-up }\end{array}$ & $\begin{array}{l}\text { Evaluation in } \\
\text { progress }\end{array}$ & $\begin{array}{l}\text { N/A. Reduction } \\
\text { of operating } \\
\text { time may } \\
\text { overcome } \\
\text { the issue of } \\
\text { operating } \\
\text { room efficiency }\end{array}$ \\
\hline Lai et al. ${ }^{10}$ & $\begin{array}{l}33 \text { patients - } \\
39 \text { breasts; } 35 \\
\text { therapeutic } \\
\text { RNSM }\end{array}$ & $\begin{array}{l}\text { Supine; } 90^{\circ} \\
\text { abduction of } \\
\text { the arm }\end{array}$ & $\begin{array}{l}2.5-5 \mathrm{~cm} \\
\text { oblique axillary } \\
\text { incision }\end{array}$ & $\begin{array}{c}287.2 \pm 77.43 \\
\min (\text { cases } 1-13) \\
235.6 \pm 30.69 \\
\text { min (cases } 14-39)\end{array}$ & $\begin{array}{c}\text { No } \\
\text { recurrence. } \\
\text { Mean } 8.6 \pm \\
4.5 \text { months } \\
\text { follow-up }\end{array}$ & N/A & N/A \\
\hline $\begin{array}{l}\text { Houvenaeghel } \\
\text { et al. }{ }^{12}\end{array}$ & $\begin{array}{l}27 \text { patients - } \\
27 \text { breasts; } 27 \\
\text { therapeutic } \\
\text { RNSM }\end{array}$ & $\begin{array}{l}\text { Supine, dorsal } \\
\text { decubitus, with } \\
\text { anteflexion of } \\
\text { the arm }\end{array}$ & $\begin{array}{l}\text { Vertical } 4-6 \text { cm; } \\
\text { on anterior } \\
\text { axillary line } \\
\text { + incision } \\
\text { for trocar } \\
\text { inferiorly }\end{array}$ & $\begin{array}{l}372.5 \text { (group 1) } \\
303.4 \text { (group 2) } \\
257.7 \text { (group 3) }\end{array}$ & N/A & N/A & $\begin{array}{l}\text { N/A. Fixed } \\
\text { costs and cost } \\
\text { of robotic } \\
\text { instruments } \\
\text { can provide } \\
\text { more costs } \\
\text { than } \\
\text { conventional } \\
\text { surgery }\end{array}$ \\
\hline Park et al.13 & $\begin{array}{c}1 \text { patient. } \\
\text { Therapeutic } \\
\text { RNSM }\end{array}$ & $\begin{array}{l}\text { Supine, dorsal } \\
\text { decubitus, with } \\
\text { anteflexion of } \\
\text { the arm }\end{array}$ & $\begin{array}{l}\text { Vertical } 6 \mathrm{~cm} \text {; } \\
\text { on anterior } \\
\text { axillary line }\end{array}$ & $409 \mathrm{~min}$ & $\begin{array}{l}\text { No } \\
\text { recurrence. } \\
12 \text { months } \\
\text { follow-up }\end{array}$ & N/A & N/A \\
\hline Rajappa et al. ${ }^{14}$ & $\begin{array}{l}1 \text { patient. } \\
\text { Therapeutic } \\
\text { RNSM }\end{array}$ & $\begin{array}{l}\text { Flat supine } \\
\text { position; arm } \\
\text { at the side of } \\
\text { the body }\end{array}$ & $\begin{array}{c}3 \mathrm{~cm} \text { on } \\
\text { midaxillary line }\end{array}$ & $330 \mathrm{~min}$ & N/A & N/A & N/A \\
\hline
\end{tabular}

RNSM: robotic nipple sparing mastectomy; N/A: Not applicable

Summary of technique, oncological outcomes, patient satisfaction and cost effectiveness in the studies analyzed. * Satisfaction described in study, but no satisfaction questionnaire cited. 
involving the nipple) in three patients, and no cases of total NAC necrosis. Infection was reported in three patients, two of which needed revision, resulting in one implant loss in one series $^{9}$. In another, reoperation was necessary for four patients, with three cases of prosthesis explantation ${ }^{12}$. Conversion to open surgery occurred in four cases, due to bleeding of internal mammary perforator (2 patients), malpositioning of incision causing technical problems (1 patient), and in Toesca et al.'s first case, due to long time of surgery (1 patient). Implant rotation was reported for 1 patient, and there was no information on whether the patient was reoperated. Complication events are summarized in Figure 2.

\section{Oncological outcomes}

There were no recurrences in the studies analyzed, with the longer follow-ups in Park et al.'s case report - 12 months -, and in Sarfati et al.'s series of cases -9 months ${ }^{9,13}$.

\section{Satisfaction}

Despite the surgery's cost and time, the satisfaction of the patient must be evaluated to determine advantages of robotic procedures. None of the studies have objective satisfaction rates published. Toesca et al. describe patient satisfaction as "high degree", but no questionnaires were used ${ }^{7}$. Sarfati et al. used the Breast-Q questionnaire before the procedure, another non-specified satisfaction questionnaire at 6 months, assessing amongst other things the aesthetic result, and the Breast-Q and the satisfaction questionnaire were planned to be used again at 12 months $^{9}$. Data are not yet available.

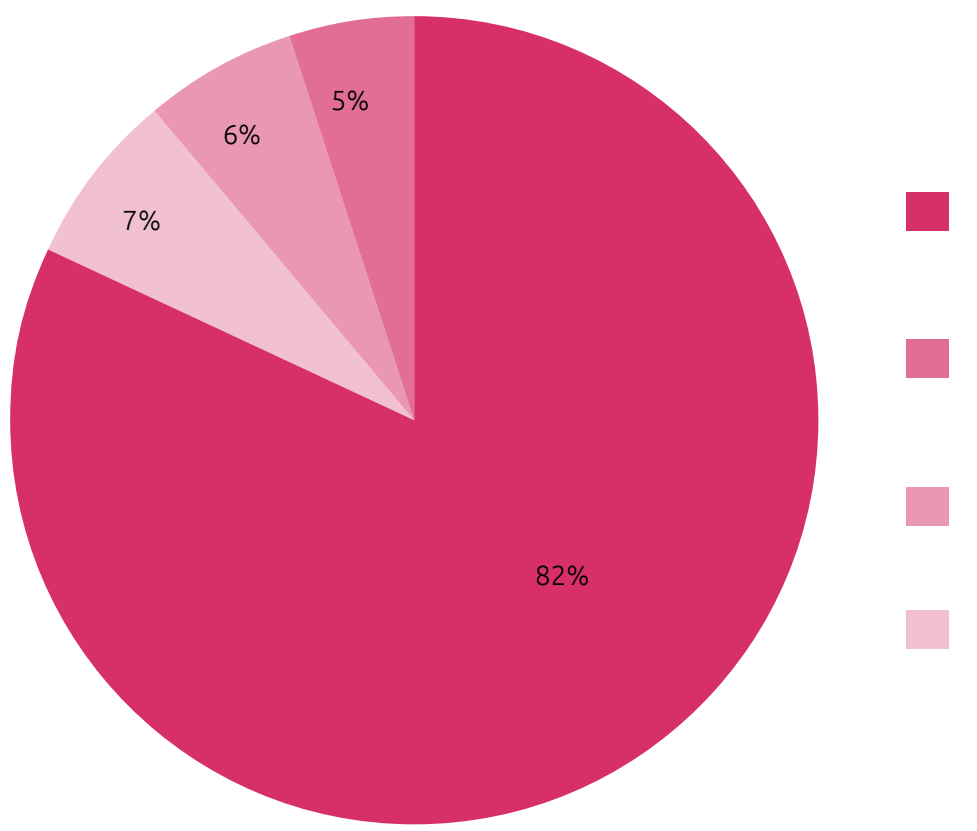

\section{Cost-effectiveness}

Robotic surgery is usually considered a very expensive procedure because of fixed and of robotic instruments costs ${ }^{12}$. The studies analyzed do not assess cost-effectiveness of RNSM.

\section{DISCUSSION}

In an era were minimal invasive techniques arise and gain popularity, robotic surgery emerges with the proposal of delivering excellence in oncological treatment at the same time as it provides good aesthetic results. According to these recent studies, with short follow-ups, indeed this technique seems to meet its promise.

The question is if it is really worth the price ${ }^{16}$. Robotics is known for its high costs, related initially to the purchase of the da Vinci Surgical System that costs between US\$1 and US $\$ 2.3$ million, added to maintenance fees, from US $\$ 100,000.00$ to US\$150,000.00 annually. The instrument arms of the robot have a maximum of 10 uses, after which they can no longer be used $^{17}$. Moreover, robotics demands adequate staff training, infrastructure upgrades, and increased operating room time. These costs are, in some cases, offset by shorter hospital stays, less trauma, bleeding and operative complications ${ }^{18,19}$.

In the context of breast surgery, bleeding is not a major problem and patients usually are discharged from hospital in a few days. NSM with immediate breast reconstruction, either with prosthesis or a flap, is one of the largest breast procedures, and for this reason, robotic surgery may be a good alternative.
No complications

I-Any deviation from normal postoperative course without need for pharmacological treatment

II-Requiring pharmacological treatment

III-Requiring surgical intervention

Figure 1. Classification of complications in robotic nipple sparing mastectomy, according to Clavien-Dindo grade. 
Centers worldwide are studying its safety and feasibility and data on its cost-effectiveness are soon expected.

Earlier this year, Linhares et al. performed the first breast robotic surgery in Brazil at Erasto Gaertner Hospital ${ }^{20}$. Other cases have followed and we soon expect a national publication of their experience.

\section{CONCLUSIONS}

RNSM with immediate reconstruction with breast implant is apparently a safe approach to the removal of the breast gland, but studies have short follow-ups of only a few months. Longer follow-up is necessary to prove oncological safety.

A

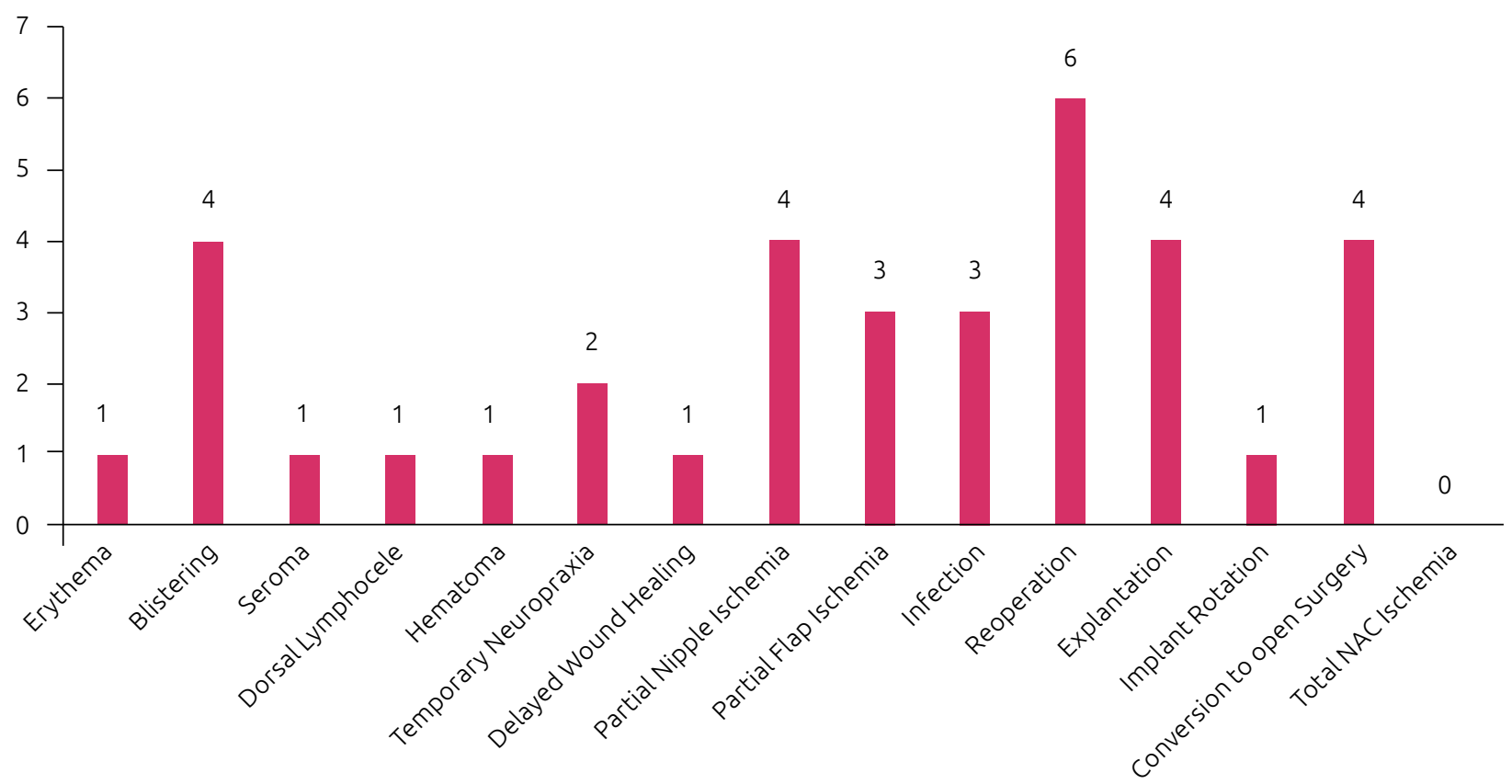

B

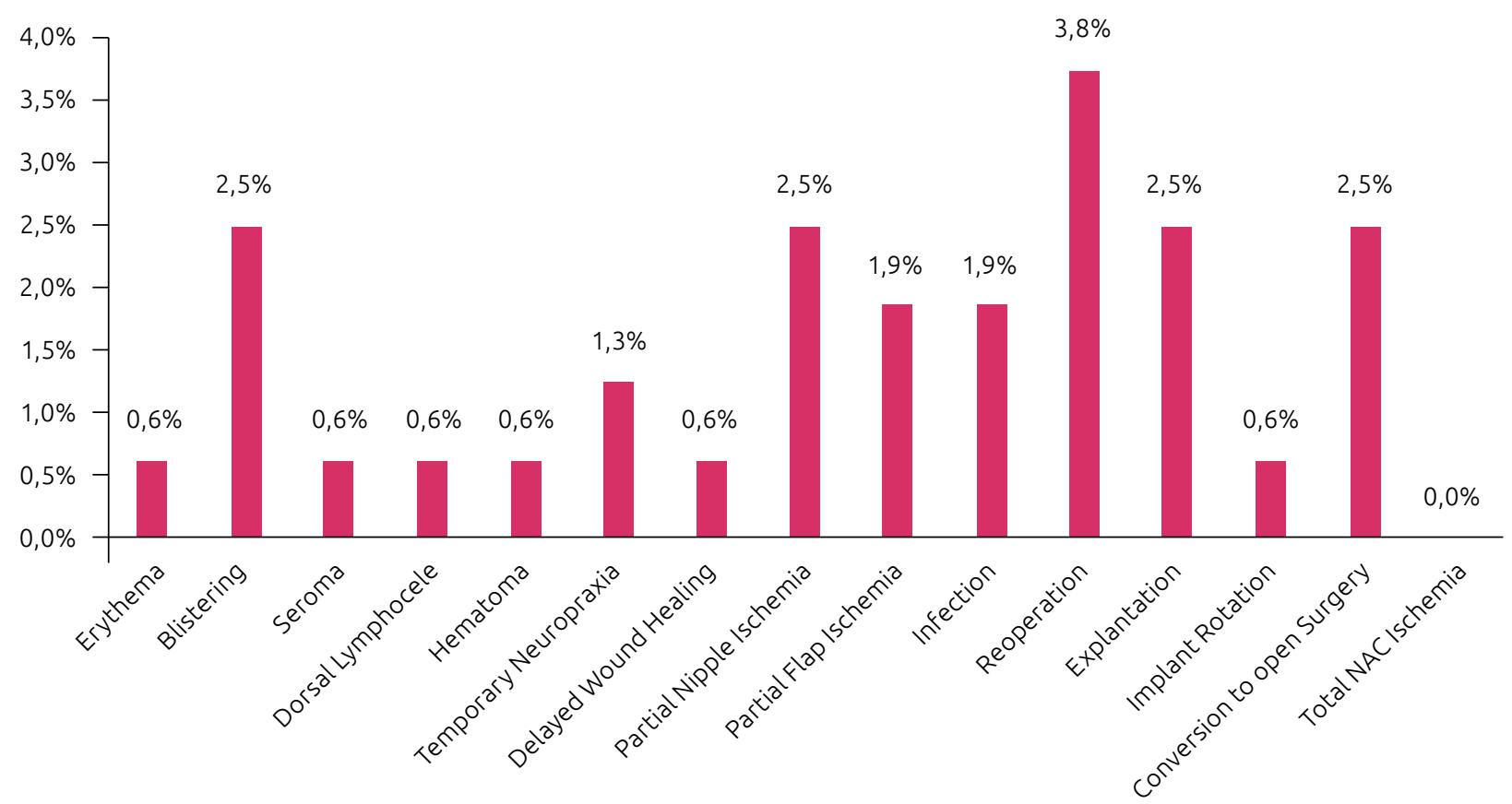

Figure 2. Complications of robotic nipple sparing mastectomy $(n=160)$ : (A) expressed in number of events (total complications = 36; no complications = 124); (B) expressed in percentage (total complications $=22,5 \%$; no complications $=77,5 \%$ ). 
Three-dimensional high resolution optics allow excellent dissection planes. Image magnification and intense lighting increase contrast of colors and visibility of structures, making dissection of the gland and recognition of all structures, especially blood vessels, more precise, thus reducing bleeding and preserving circulation to the nipple areolar complex. High precision movement, stability due to tremor elimination, articulation and motion of instruments enable good mobility around the curvature of the breast cupola ${ }^{7,9,10}$.

Complication rates for RNSM are low (23\%), mostly minor ones, with only $3 \%$ of conversion and $4 \%$ of reoperations. Ischemia and necrosis are rare (5\%), and no total skin or NAC necrosis were reported.

There are no studies so far that analyze cost-effectiveness for robotic breast surgeries, but the fast learning curve helps to reduce operating room time and consequently the costs. Robotic instruments are known to be expensive, so as maintenance for the robot, but strategies have been proposed to reduce $\operatorname{costs}^{17}$ and soon new competitors for the Da Vinci are expected to enter the robotic market ${ }^{20}$.

In the search for increasingly less invasive surgeries, robotics seems to meet what is proposed without compromising oncological safety and keeping up with high-satisfaction aesthetic results. Longer follow-up and cost-effective analyzes will determine if this technique will be consolidated.

\section{AUTHORS' CONTRIBUTION}

P.C. : Conceptualization, Data curation, Formal analysis, Project administration, Writing - original draft.

D.M.P. : Conceptualization; Project administration, Writing review \& editing.

N.C.S.: Conceptualization, Data curation; Writing - review \& editing. J.M.C. : Investigation, Visualization.

F.S.O.: Methodology; Visualization.

\section{REFERENCES}

1. Urban C, Lima R, Schunemann E, Spautz C, Rabinovich I, Anselmi K. Oncoplastic principles in breast conserving surgery. The Breast. 2011;20(Suppl. 3):S92-S95. https://doi. org/10.1016/s0960-9776(11)70302-2

2. Hinton C, Doyle P, Blamey R, Davies C, Holliday H, Elston C. Subcutaneous mastectomy for primary operable breast cancer. Br J Surg. 1984;71(6):469-72. https://doi.org/10.1002/ bjs. 1800710623

3. Toth B, Lappert P. Modified skin incisions for mastectomy: the need for plastic surgical input in preoperative planning. Plast Reconstr Surg. 1991;87(6):1048-53. https://doi. org/10.1097/00006534-199106000-00006

4. Kroll S, Schusterman M, Tadjalli H, Singletary S, Ames F. Risk of recurrence after treatment of early breast cancer with skinsparing mastectomy. Ann Surg Oncol. 1997;4:193-7. https://doi. org/10.1007/BF02306609

5. Viegas JF, Lichtenfels M, de Souza ABA, Vollbrecht B, Laitano Neto F, Zerwes FP, et al. Aesthetic outcome and oncological safety of nipple-sparing mastectomy. Mastology. 2019;29(1):3-8. https://doi.org/10.29289/259453 9420190000418

6. Leff D, Vashisht R, Yongue G, Keshtgar M, Yang G, Darzi A. Endoscopic breast surgery: where are we now and what might the future hold for video-assisted breast surgery? Breast Cancer Res Treat. 2011;125:607-25. https://doi.org/10.1007/ s10549-010-1258-4

7. Toesca A, Peradze N, Manconi A, Galimberti V, Intra M, Colleoni $\mathrm{M}$, et al. Robotic nipple-sparing mastectomy for the treatment of breast cancer: Feasibility and safety study. The Breast. 2017;31:51-6. http://dx.doi.org/10.1016/j. breast.2016.10.009
8. Toesca A, Peradze N, Galimberti V, Manconi A, Intra M, Gentilini O, et al. Robotic Nipple-sparing Mastectomy and Immediate Breast Reconstruction With Implant: First Report of Surgical Technique. Ann Surg. 2017;266(2):e28-30. https:// doi.org/10.1097/SLA.0000000000001397

9. Sarfati B, Struk S, Leymarie N, Honart JF, Alkhashnam $\mathrm{H}$, Fremicourt KT, et al. Robotic Prophylactic NippleSparing Mastectomy with Immediate Prosthetic Breast Reconstruction: A Prospective Study. Ann Surg Oncol. 2018;25:2579-86. https://doi.org/10.1245/s10434-018-6555-х

10. Lai HW, Wang CC, Lai YC, Chen CJ, Lin SL, Chen ST, et al. The learning curve of robotic nipple sparing mastectomy for breast cancer: An analysis of consecutive 39 procedures with cumulative sum plot. Eur J Surg Oncol. 2019;45(2):125-33. https://doi.org/10.1016/j.ejso.2018.09.021

11. Sarfati B, Honart J, Leymarie N, Kolb F, Rimareix F. Robotic-assisted Nipple Sparing Mastectomy: A feasibility study on cadaveric models. J Plast Reconstr Aesthet Surg. 2016;69(11):1571-2. https://doi.org/10.1016/j.bjps.2016.08.007

12. Houvenaeghel G, Bannier M, Rua S, Barrou M, Heinemann A, Troy E, et al. Breast cancer robotic nipple sparing mastectomy: evaluation of several surgical procedures and learning curve. World J Surg Oncol. 2019;17. https://doi.org/10.1186/s12957-019-1567-y

13. Park HS, Kim JH, Lee DW, Song SY, Park S, Kim SI, et al. Gasless Robot-Assisted Nipple-Sparing Mastectomy: A Case Report. J Breast Cancer. 2018;21(3):334-8. http://dx.doi.org/10.4048/ jbc.2018.21.e45

14. Rajappa SK, Mch RK, Garg S, Ram D. Robotic nipple-sparing mastectomy: The first experience from Indian subcontinent. The Breast J. 2018;24(6):1114-5. https://doi.org/10.1111/tbj.13146 
15. Dindo D, Dermatines N, Clavien PA. Classification of Surgical Complications A New Proposal With Evaluation in a Cohort of 6336Patients andResults ofaSurvey.AnnSurg.2004;240(2):20513. http://doi.org/10.1097/01.sla.0000133083.54934.ae

16. Warren H, Dasgupta P. The future of robotics. Investig Clin Urol. 2017;58(5):297-8. http://dx.doi.org/10.4111/icu.2017.58.5.297

17. Nayeemuddin M, Daley S, Ellsworth P. Modifiable Factors to Decrease the Cost of Robotic-Assisted Procedures. AORN J. 2013;98(4):343-52. https://doi.org/10.1016/j.aorn.2013.08.012
18. Childers C, Gibbons M. Estimation of the Acquisition and Operating Costs for Robotic Surgery. JAMA. 2018;320(8):835-6. https://doi.org/10.1001/jama.2018.9219

19. Khorgami Z, Li WT, Jackson TN, Howard A, Sclabas G. The cost of robotics: an analysis of the added costs of robotic-assisted versus laparoscopic surgery using the National Inpatient Sample. Surg Endosc. 2019;33:2217-21. https://doi.org/10.1007/s00464-018-6507-3

20. Linhares J, Hatschbach S, Tsunoda A, Groth A. To Boldly Go Where No Man Has Gone Before. Mastology. 2019;29(1):2-3. https:doi.org/10.29289/2594539420190000463 